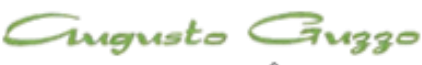

REVISTA ACADEMICA

\title{
A utopia do isolamento e o reflexo no trabalho
}

\author{
Sueli Ferreira Schiavo ${ }^{1}$ \\ Recebido em: 21/09/2013. Aprovado em: 22/11/2013. Disponibilizado em: 20/12/2013 \\ 1. Sueli Ferreira Schiavo é psicóloga, Doutoranda em comunicação, mestre em Comunicação pela UNIP/2013.
}

\section{Resumo}

Viver em grandes centros urbanos significa ter condições de sustento obtido pelo apoio familiar/comunitário, por patrimônio herdado ou pelo trabalho remunerado. No é possível se locomover e dar conta das diferentes demandas que surgem sem recursos financeiros. Porém a condição social que o trabalho remunerado impõe para a pessoa se sustentar pode significar um custo do qual nem sempre se tem consciência do que significa. Neste estudo, como requisito parcial da conclusão do curso Incomunicação e Loucura, se reflete sobre o trabalho enquanto um meio que pode incidir sobre a comunicação interpessoal e intrapessoal em um determinado período na vida da pessoa, de modo a poder lhe comprometer a sanidade mental (como trabalhadora) devido às opressões exercidas pelos regulamentos, principalmente quando seduzida pelo consumismo da vida em sociedade. Está fundamentado na visão de teóricos como Zigmunt Bauman, Louis Althusser e Monica Maria Martins de Souza.

Palavras-chave: trabalho, loucura, incomunica

\begin{abstract}
Live in large urban centers means of livelihood conditions have gotten by community / family support for legacy assets or by paid work. In is possible to get around and to account for the different demands that arise without financial resources. But the social condition that paid work requires the person to sustain itself can mean a cost which is not always aware of what it means. In this study, as a partial requirement of cource Intercommunication and Madness, is reflected on the work as a medium that can focus on the interpersonal and intrapersonal communication in a given period in one's life, so could compromise her sanity (as a worker) due to the oppressions exercised by the regulations, especially when seduced by consumerism of society. Is based on the view of theorists like Zigmunt Bauman, Louis Althusser and Monica Maria Martins de Souza.
\end{abstract}

Keywords: Work, madness, intercomunication 


\section{Introdução}

O modelo de sociedade nos grandes centros urbanos deste início de século XXI tem sido marcado por uma forma de vida capitalista que estimula o consumismo. As relações interpessoais refletem superficialidade e percepção de isolamento social, uma carência de vida política ativa. Zigmunt Bauman (2005) fundamenta em seu livro Vida Líquida diversos outros motivos que levaram a este estado de coisas.

A partir de um determinado momento da história social, constituiu-se um modelo de interação que promoveu a convivência em grandes espaços urbanos, para acolher maior densidade de pessoas. É possível perceber no encontro deste contingente, as pessoas mais isolam e fragmentam do que interagem. Um exemplo disso é a virada paulista que reúne milhares de pessoas em torno de um tema, mas essas pessoas não interagem entre si.

Martín-Barbero (1997) em seu livro Dos meios às mediações alude a essa questão do estar junto, mas não em comunhão, ao tratar do sentido do tempo e das festas nas culturas populares. Para esse autor há uma organização do tempo em torno de gerar a produção. Dessa forma se separa o tempo do trabalho e o tempo do ócio. As festas são transformadas em espetáculos para serem vistos e não para serem vivenciados. Assim, a contagem do tempo, o dinheiro, o valor do trabalho, a acumulação, promovem uma fragmentação social.

Esta relação de “juntos, porém separados" é percebida também nos lares, onde as pessoas ficam restritas à espaços "ilhas" dentro destes "lares". Eles são hipoteticamente estruturados em "família" cuja característica é a mais diversa possível, e são compostas até mesmo de um único membro. Isso ocorre porque na contemporaneidade, a era do conhecimento alicerçada pelo avanço tecnológico consome o tempo das pessoas nos aparatos eletrônicos pelos quais elas se falam até mesmo na mesa de jantar. Elas são assoberbadas por tamanha carga de compromissos tecnológicos que não refletem sobre o afastamento humano em sua existência, o que é uma alienação. Esta situação vivida na ambiência mais íntima do ser humano promove uma idiossincrasia que abre portas, e permite a sua reprodução em outros ambientes. Um deles é o da empresa onde a "loucura profissional" fica facilitada.

A subjetividade é algo que se constrói na relação com o outro e nas trocas sociais. Quanto mais acesso a diferentes pessoas em diferentes contextos tanto melhor. Quando uma pessoa se referencia em diferentes ambientes e relações sociais ela tem condição de desenvolvimento pessoal mais satisfatório para a condição de vivência urbana. Esse modelo que limita o compartilhamento de ideias e o acesso ao convívio não empodera a pessoa. Pelo contrário sentir-se isolada e sem o contato de referências próximas torna a pessoa refém de um ritmo de vida que não lhe propicia uma cidadania ativa. O isolamento e a submissão a muitas regras justifica uma série de outras necessidades sociais que passam a surgir para complementar a ausência do afeto e do contato humano.

Comparando com relação ao ambiente de trabalho também é possível perceber que o isolamento não necessariamente ocorre por ausência de outras pessoas que estejam próximas. Mesmo em situações em que existem colegas de trabalho na proximidade a pessoa pode se sentir só. Conforme o tipo de ambiência organizacional e de regramento pode propiciar mais um modelo de competição do que de cooperação. Nessa situação, o isolamento em que a pessoa se percebe passa a ocorrer pela prevalência de outros fatores, tais como a possibilidade de perda do trabalho remunerado. E da mesma forma representa não empoderamento. 
Como exemplo de que esse modelo de sociedade coloca as pessoas em casulos (denominados "lares") e que isso justifica uma série de outras situações, como a manutenção de níveis de produção em massa para atender às diversas unidades de lares. Os mesmos itens de consumo são encontrados nos diferentes lares. Existe toda uma cultura midiática que auxilia a entender o que precisa ter nos lares. As pessoas aprendem pela mídia como devem ser preparadas as diferentes coisas: organização da casa, comida, etc. As estruturas culturais promovem a acomodação e adequação a esse modelo. Aí se justifica a necessidade de produção em massa desses itens de consumo. Com isso também se justifica a necessidade de criação de locais de trabalho para as pessoas nessas unidades de alta produção. Torna o homem uma peça da engrenagem. Quanto mais distante do cultivo do próprio alimento e da convivência comunitária mais dependente o homem fica do modelo produtivo em que está inserido. Precisa consumir e tudo será adquirido. Para isso são necessários recursos financeiros e trabalho remunerado. Esse processo de massificação caracteriza a acumulação de carências sociais.

\section{O trabalho como um meio}

Considerando essas questões levantadas, os ambientes organizacionais de produção e os ligados a essa produção já se constituem dentro de uma utopia. Estar no isolamento (como no caso dos lares, dos escritórios e outros espaços de trabalho) recebendo pelos meios de comunicação a informação daquilo em que se tem que prestar atenção, isso afasta as pessoas dos espaços públicos e da vida política. Debord (2003) explica sobre essa questão "a realidade considerada parcialmente reflete em sua própria unidade geral um pseudo mundo à parte, objeto de pura contemplação". (DEBORD, 2003, p. 2). As imagens fazem uma representação do que se passa no mundo real, criam uma ilusão de se estar integrado a um ambiente que culmina pelo distanciamento das pessoas. Tende a parecer como algo natural como se sempre tivesse sido assim. O fato é que em grandes centros urbanos com alta densidade de pessoas existem situações de isolamento e de competição. É incompreensível que isso possa se constituir como condição adequada para o viver humano.

Dentro dessa perspectiva, quando as coisas não vão bem (o que acontece com muita frequência) se atribui culpa às pessoas individualmente. Em situações de violência que ocorrem de diferentes ordens: transtornos de saúde, crises familiares, (dificuldades de adequação do modelo) busca-se não analisar em relação à convivência social e comunitária, analisa-se em relação à falha da pessoa independentemente da lógica do modelo em que ela vive.

As unidades produtivas das corporações reproduzem as mesmas condições que as de habitação. As pessoas podem estar em um conjunto em que participam de operação de máquinas, ou estão sentadas atrás de uma escrivaninha, ou em atividade de atendimento, mas podem não se sentir em um coletivo que as apoiem. Esse tipo de percepção acontece porque a submissão a regras que não ajudaram a construir e a ausência de soluções conjuntas, podem limitar seus comportamentos. Em algumas situações a pessoa pode sentir que não lhe permite dignidade o cotidiano de suas funções e que isso a isola de condições mais saudáveis. Esse "faz de conta" de que está tudo bem assim mesmo vai propiciando esse contexto de loucura social.

Nas organizações há um processo de adaptação dos corpos ao modelo de ordem vivido ali. É um modelo forçado, as pessoas observam as dificuldades de seus colegas e algumas vezes nem expressam suas próprias 
necessidades. E assim soluções que poderiam ser compartilhadas para desfrutarem do apoio coletivo não acontecem. Sob a pressão de cumprimento de metas e desafios organizacionais, muito esforço é demandado. Para garantir a manutenção do trabalho e se sentir inserida naquele ambiente organizacional a pessoa se aliena de si e isso se constitui em loucura. Não há tempo para reflexão sobre o que se passa no dia a dia da organização, o ritmo de trabalho não permite, outros irão pensar por ela sobre soluções, ela receberá isso pronto. A não participação na busca de solução promove a possibilidade da pessoa se sentir em um processo de fragmentação. Há condições e regras organizacionais que não suportam algumas questões humanas. A medida que os assuntos não vão sendo tratados, essa situação contribui para desconforto e alienação.

A loucura corporativa acolhe o homem empenhado em crer que esse modelo social em que vive seja sustentável. Esse acolhimento possui um vazio de sentido relacionado às situações que implicam em dificuldades humanas não atendidas. Existem as ameaças de diferentes ordens relacionadas à sobrevivência que não está dada, precisa ser conquistada cotidianamente. Além disso as agruras urbanas comprometem as soluções. Uma das agruras é o transporte coletivo lotado no horário em que todos precisam estar ao mesmo tempo ocupando espaços em que não cabem todos. As vias de circulação congestionadas, acidentes e manifestações de diferentes ordens demostram que o sistema não vai bem, mas as coisas não mudam.

Esse "faz de conta" no corpo(r)ativo (Souza, 2013) já nasceu contaminado. Está dentro de um modelo de sociedade em que as pessoas estão vivenciando de forma isolada os mesmos desafios que outras pessoas também estão vivenciando, mas isso não lhes permite trocas e soluções compartilhadas nem os devidos apoios. As necessidades comunicativas na vida social e dentro das organizações (como no caso de onde se situa o trabalho remunerado) estão inseridas pela análise de Louis Athusser como "estruturas ideológicas de poder". Conforme esse autor, as diferentes instituições reproduzem $\mathrm{O}$ mesmo modelo de orientação social, geralmente vertical em termos de poder, isso diminui a condição de critica e molda o comportamento.

As experiências que as pessoas possuem, por exemplo, nas artes (e outras de seus contextos de vida e até da educação) só são importantes se isso contribuir para aumentar a produtividade do trabalho que realizam, caso contrário não contam. Nessas condições a pessoa pode se sentir vulnerável. No momento em que não percebe que há reconhecimento por outras competências acumuladas em suas vivências anteriores, a pessoa irá precisar de novos recursos para se sentir inserida. Quando a estrutura organizacional não percebe as pessoas enquanto únicas, que tem uma história de vida, essas podem se sentir isoladas e fragilizadas.

Esse modelo que não empodera, segmenta em diferentes papéis organizacionais a serem desempenhados, promove uma ameaça para a pessoa como membro dessa engrenagem organizacional. Se os espaços comunicacionais não acolherem ou apresentarem as condições para solucionar entraves (de ordem pessoal e social) a fragilização pelo sistema é concreta. Para estar aceita a pessoa se subordina e se aliena de suas necessidades. O consumismo pode ser uma das saídas para compensar todo esse esforço de manutenção do status quo. Conforme Souza (2013) essa submissão ocasionada pela imposição de normas, cumprimento de horário, dedicação expressa, representa uma possibilidade de manter a vinculação ao trabalho uma vez que, esta se encontra constantemente ameaçada. Esse estado, em que se percebe a ameaça frequente, eleva o nível de estresse do 
organismo ao longo do tempo. Como os espaços não acolhem as necessidades humanas e sociais, os rituais organizacionais vão alimentando a lógica adaptativa e a alienação vai se aprofundando.

Dentro da loucura urbana o que é mais ético ou menos ético precisa ser analisado e avaliado dentro de um contexto. Isso devido à precarização das relações em função do modelo de sociedade vigente. No processo de sedução a que os sujeitos estão submetidos a organização passa a dizer para o sujeito (trabalhador) que a organização é muito importante para ele, pois lhe garante o atendimento de seu sustento. Geralmente isso é dito de forma invertida, como se o trabalhador fosse muito importante para a organização. Pode ser feito assim porque ambos os lados sabem exatamente quem está no poder. O fato é que isso não permite clareza de percepção de quão precárias são as condições de saúde em ambientes dessa natureza. Como explica Bauman (2005) é um modelo fluido, os limites são flexíveis e quase não há limites sobre aquilo que pode acontecer.

As relações de vínculos de trabalho com diferentes formas de contratação, do tipo pessoas jurídicas em lugar de pessoas físicas, por exemplo, ampliam oportunidades para novos trabalhadores, mas tornam as condições mais precárias. Isto porque as regras trabalhistas são dribladas. Os trabalhadores em diferentes condições dentro da organização também representam ameaças uns aos outros. Assim situações como a precarização das condições de trabalho são comuns de ocorrerem e servem para mostrar que há níveis de melhor reconhecimento e que serão desejados. Trabalhador precarizando o trabalho de outro trabalhador. Os proprietariados do negócio organizacional vão se tornando uma elite distante da realidade do chamado "chão de fábrica".
As relações vão se tornando também sem sentido porque não se pode dizer o que precisaria ser tratado, discutido, mudado. Para a pessoa sobreviver no modelo precisa estar aceita. Os trabalhadores conhecem sobre sua fragilidade no sistema organizacional. Um exemplo do que acontece em serviços de telemarketing é a ginástica laboral, Dependendo de como se transforma em obrigação de participação, aquilo que é para promover a saúde pode acabar sendo percebida pelo trabalhador mais como uma regra para que não se ausente do trabalho por comprometimento de sua saúde do que uma educação. A forma como é conduzida a inserção das atividades pode demonstrar o tratamento à pessoa para que esta conquiste condições pessoais de uma vida mais digna.

A questão simbólica corporativa está relacionada aos processos intersubjetivos em que o que está em jogo é a submissão (Souza, 2013). O processo vai se desenvolvendo de tal forma que o medo é todo o tempo provocado sutilmente pelas ameaças e o assujeitamento é a condição de manutenção dentro do modelo. Isso se incorpora de tal forma que é automatizado. Os vínculos são comprometidos pela condição do jogo organizacional e a alienação se comporta como uma forma de diminuir a crítica ao sistema e garantir a sobrevivência.

Forma de lidar com essas limitações são encontradas nas artes, nos sonhos, na filosofia em que se está livre das condições limitantes da existência humana. Nos jogos também o comportamento lúdico (Huizinga, 2000) contribui para o aprendizado social de regras dissimulando a realidade.

\section{Considerações finais}

No curso de Incomunicação e Loucura tivemos a oportunidade de discutir sobre questões relacionadas com a situação de conflito comunicativo no trabalho. Foi 
abordado sobre o quanto isso pode se constituir como loucura. Esse modelo é reflexo da forma como está constituída a sociedade contemporânea cuja participação e cidadania ativa é limitada. Há falta de compartilhamento das dificuldades humanas e sociais. As pessoas estão atomizadas e divididas em contextos de vida que não lhes permite um empoderamento social. Dessa forma não se ajudam nem se apoiam suficientemente. Para acolher a necessidade do outro a pessoa precisa ter sua própria necessidade acolhida. Em um ambiente que não propicia trocas e subordina às regras $\mathrm{o}$ isolamento se configura. Em uma ambiência não comprometidas com as necessidades individuais e coletivas há um silenciamento. Nessas condições as pessoas estão em um conjunto, mas não compõem um ambiente socialmente humanizado. Com o intuito de sobreviver ao modelo rebaixam a crítica e ficam alienadas ao sistema. Isso não permite uma vivência plena de satisfação. As pessoas passam a buscar no consumismo uma forma de suprir suas carências. Esse modo de agir passa a se tornar um recurso para suprir a carência e ao mesmo tempo, isso as submetem ainda mais ao sistema. O que gera alienação e mais subordinação realimenta a loucura organizacional.

\section{Referências Bibliográficas}

1. ALTHUSSER, Louis. Aparelhos Ideológicos de Estado. Rio de Janeiro: Graal, 1998.

2. BAUMAN, Zygmunt. Em busca da política. Rio de Janeiro: Zahar. 1999. Vida Líquida, Rio de Janeiro: Zahar, 2005.

3. DEBORD, Guy. A sociedade do espetáculo. Fonte Digital, 2003. Disponível em: <http://www.ebooksbrasil.org/eLibris /socespetaculo.html>. Acesso em 18.05.2013.

HUIZINGA, Johan. Homo Ludens. São Paulo: Editora Perspectiva, 2000.

4. MARTÍN-BARÉRO, Jesús. Dos meios às mediações: comunicação, cultura e hegemonia. Rio de Janeiro: Editora UFRJ. 1997.

5. SOUZA, Monica Maria Martins de. Comunicação Coporativa: os textos das normas e as normas como textos culturais produtores de loucura nas empresas. Mediatel: Curso Incomunicação e Loucura, 2013. 